\title{
The Dark Side of Interaction Design
}

$\begin{array}{ll}\text { Yvonne Rogers } & \text { Margot Brereton } \\ \text { UCLIC, UCL } & \text { QUT } \\ \text { London, WC1E 6BT, UK } & \begin{array}{l}\text { Brisbane, Australia } \\ \text { y.rogers@ucl.ac.uk }\end{array} \\ \text { Paul Dourish } & \text { Jodi Forlizzi } \\ \text { UCI } & \text { CMU } \\ \text { Irvine, CA, USA } & \text { Pittsburgh, PA, USA } \\ \text { jpd@ics.uci.edu } & \text { forlizzi@cs.cmu.edu } \\ \text { Patrick Olivier } & \\ \text { Monash University } & \\ \text { VIC 3145, Australia } & \\ \text { patrick.olivier@monash.edu } & \end{array}$

Permission to make digital or hard copies of part or all of this work for personal or classroom use is granted without fee provided that copies are not made or distributed for profit or commercial advantage and that copies bear this notice and the full citation on the first page. Copyrights for third-party components of this work must be honored. For all other uses, contact the owner/author(s).

CHI'20 Extended Abstracts, April 25-30, 2020, Honolulu, HI, USA C) 2020 Copyright is held by the owner/author(s).

ACM ISBN 978-1-4503-6819-3/20/04.

https://doi.org/10.1145/3334480.3381070

\begin{abstract}
This panel will provoke the audience into reflecting on the dark side of interaction design. It will ask what role the $\mathrm{HCI}$ community has played in the inception and rise of digital addiction, digital persuasion, data exploitation and dark patterns and what to do about this state of affairs. The panelists will present their views about what we have unleashed. They will examine how 'stickiness' came about and how we might give users control over their data that is sucked up in this process. Finally, they will be asked to consider the merits and prospects of an alternative agenda, that pushes for interaction design to be fairer, more ethically-grounded and more transparent, while at the same time addressing head-on the dark side of interaction design.
\end{abstract}

\section{Author Keywords}

Interaction Design, dark side; digital addiction, dark patterns, nudging, data exploitation

\section{CSS Concepts}

- Human-centered computing Human computer interaction (HCI)

\section{Introduction}

A backlash against interaction design is beginning to materialize in social media and the press; criticizing us for our role in the rise in digital addiction, fake news, social media abuse, etc. At the same time there is growing concern about the role of the interface in enabling data exploitation through the pervasive use of 
dark patterns. To address these, the panel will be asked whether they think we are to blame for letting the genie out of the bottle through our proliferation of interaction techniques, prescriptive mentality and abundance of guidance. And what can we do about it?

For decades, interaction designers have been responsible for developing interface techniques that are now commonly used to nudge users, for example, to click on ads, stay on a site, keep playing a game and come back for more. In addition, a proliferation of books and guidelines have been published that explain how to change users' behavior through designing persuasive interventions at the interface. Many of these are intended to be for personal improvement or social good, such as to help people get fitter, improve their work productivity, be more motivated, reduce energy consumption and so on. However, the same techniques can also be used for more nefarious ends. Referred to as dark patterns, they have become UX's bag of tricks that websites and apps use to make users do things they didn't intend doing, such as buying or signing up for something.

Nudging techniques were originally derived from behavioral economics and social psychology in the 90s [7]. Since then, they have been applied in $\mathrm{HCI}$, through being used to design all manner of apps, ambient displays and other technologies, that suggest, compare and push certain kinds of information or reminders to make people behave in a certain way - often with impressive results. Eric Schaffer [6] points out how many websites were essentially designed to persuade or influence rather than enable users to perform their tasks. For example, many online shopping sites are in the business of selling services and products, where a core strategy is to entice people to buy what they might not have thought they needed. Online shopping experiences are all about persuading people to buy, involving encouraging, suggesting, or reminding the user of things that they might like or need. Many online travel sites try to lure visitors to purchase additional items (such as hotels, insurance, car rental, car parking, or day trips) besides the flight they originally wanted to book, and they will add a list full of tempting graphics to the visitor's booking form, which then has to be scrolled through before being able to complete the transaction. Some online sites will blatantly add items to a customer's shopping basket (for example, insurance, special delivery, and care and handling) that the shopper has to deselect if not desired or start all over again.

This deceptive approach to UX has been described by Harry Brignull as dark patterns [3]. Natasha Loma [5] has since pointed out how dark pattern design is "deception and dishonesty by design." She notes how many kinds of dark patterns there are now that are used to deceive users. A well-known example that most of us have experienced is unsubscribing from a marketing mailing list. Many sites go to great lengths to make it difficult for you to leave; you think you have unsubscribed, but then you discover that you need to type in your email address and click several more buttons to reaffirm that you really want to quit. Then, just when you think you are safe, they post a survey asking you to answer a few questions about why you want to leave. Like Harry Brignull, she argues that companies should stop doing this, and instead, adopt fairer and ethical design where users have to opt in to any actions that benefit the company at the expense of the users' interests. 
Data exploitation: But, not only are dark patterns used to increase a company's revenue, they have become integral to how data is collected about users - the outcome of which in itself has become a valuable commodity. Many of the websites, apps and social media we visit and inhabit, harvest all sorts of data from our online behavior, without telling us exactly what they are collecting [1]. This data is often then sold onto third parties, and used by companies and governments to identify and profile individuals, that can be used to predict and manipulate subsequent user behavior, making more fine-tuned decisions about when and what to present, and how to notify and nudge. Hence, it is not only dark patterns per se that are problematic, but the relationship between them and how the data collected in the process is subsequently exploited that is unacceptable. To help unpack this further escalation, we propose framing it in terms of three levels:

(i) at the micro-level, where the assumed default is to set the interface so that the user will buy purchases or insurance or take up a free trial (e.g. Netflix, Amazon Prime). This often requires them to sign up and provide their credit card details that then default to monthly payments after the free trial period. Many users forget and if they do, the onus is on them to find a way of navigating the company's interface to stop the order. Many companies also make it very difficult to find the cancel clause on their website.

(ii) at the meso-level, where interaction techniques have been developed that can't really be identified as bad in themselves, that is in one single action, but which the cumulative effect is to keep the user within the walls of an app, and in so doing generate valuable data for the company.

(iii) at the macro-level, where the apps comprise both meso-level interactions of micro-level patterns; but for which the whole result of their use together can be damaging because they leverage the network effects of social media and human psychological vulnerabilities to knowingly effect that damage. That is, the business models of these "service" providers depends upon what are essentially some of the most negative

consequences of social comparison, and the ability of a platform to make its users less happy, but at the same time seemingly dependent on the service to be more happy.

One suggestion is to call out how the interplay between the three levels operate, by recognising the different qualities of and levels of interactions and the services they realise, at:

1. The user level - uncovering, documenting and quantifying the patterns. This could be done using 'reverse-usability', where we seek to uncover just what these techniques are doing, why they are so effective and if possible find ways of disrupting them.

2. The application level: Understanding how the micro patterns interact, and the network effects of these interaction.

3. The system level: Understanding how the lower levels are serving the business model of the companies delivering these services. This involves aligning with the data justice 
communities, who are concerned with the closed nature of data that is captured by many of these services that fuels the business models.

In examining these interdependences we can also start to consider what others ways are there for managing better the relationship between UX and data exploitation? In particular, can the interface be designed so that people can take more control of their lives and their data?

Finally, the panel will consider UX approaches to addressing the challenges of digital addiction [2]. Is the way forward to help people overcome their addictions through designing apps that help them refrain from and reduce screen time? Or is it too little and too late?

Each panelist will be asked to speak for 5 minutes, allowing for a full blown discussion with the audience. We want to encourage a lively debate, given how topical and controversial the problem is.

\section{References}

[1] A world of data exploitation. https://privacyinternational.org/recommendationprinciple-or-safeguard/world-data-exploitation

[2] Raian Ali, Emily Arden-Close and John McAlaney. 2018. Digital addiction: how technology keeps us hooked. http://theconversation.com/digitaladdiction-how-technology-keeps-us-hooked97499

[3] Harry Brignull. Dark Patterns. http://darkpatterns.org.
[4] Fogg, B.J. 2003. Persuasive Technology: Using Computers to Change What We Think and Do. San Francisco, CA, USA: Morgan Kaufmann Publishers.

[5] Natasha Loma. 2018. WTF is a dark pattern? https://techcrunch.com/2018/07/01/wtf-is-darkpattern-design/

[6] Eric Schaffer. 2009. Beyond Usability: Designing Web Sites for Persuasion, Emotion and Trust. https://www.uxmatters.com/mt/archives/2009/01 /beyond-usability-designing-web-sites-forpersuasion-emotion-and-trust.php

[7] Richard Thaler and Cass Sunstein. 2008. Nudge. Yale University Press. 